\title{
Influence of Glycerol Additive on the Chemical Structure, Hydrophobicity, Morphology and Optical Properties of Sol-gel Based Zirconia Coatings
}

\author{
Uzma K.H. Bangi, ${ }^{1, *}$ Rabiya S. Gafari, ${ }^{2}$ Rajendra C. Pawar, ${ }^{3}$ Hae-Noo-Ree Jung ${ }^{4}$ and Hyung-Ho Park ${ }^{4}$
}

\begin{abstract}
This work represents the influence of glycerol additive on the chemical structure, hydrophobicity, morphology and optical properties of the sol-gel based zirconia coatings. The drying control chemical additives (DCCAs) are found to sustain the porous structure of the materials, which reduces the risk of cracking. Among various DCCAs like oxalic acid, glycerol (GLY), formamide etc., GLY is observed to be an effective DCCA because of its low vapor pressure $\left(2.13 \times 10^{-6}\right.$ bar at $\left.20^{\circ} \mathrm{C}\right)$. Therefore, the effect of GLY additive on the properties of zirconia coatings has been studied by varying the molar ratio of GLY:Zr ${ }^{4+}$ from 0 to 2.15. During the sol-gel process the molar ratio of ZrPro: $\mathrm{PrOH}$ : Acac: $\mathrm{H}_{2} \mathrm{O}$ was maintained constant as 1:79.8:0.615:35.08, respectively with $0.1 \mathrm{M} \mathrm{HCl}$. The Fourier-transform infrared (FTIR) and X-ray photoelectron (XPS) analyses revealed that the coating material was zirconia. Scanning electron microscope (SEM) images manifested the porous morphology of the zirconia coatings, having the optical transmission larger than $90 \%$. Moreover, the porous nature of the zirconia coatings was confirmed by calculating their refractive indices. The zirconia coatings synthesized using the GLY: $\mathrm{Zr}^{4+}$ molar ratio of 0.429 exhibited the high contact angel of $108^{\circ}$ and low refractive index of 1.66, which evidenced their optically transparent and hydrophobic characteristics.
\end{abstract}

Keywords: Glycerol; Zirconia coatings; Refractive index; Contact angle; Transparent; Hydrophobic.

Received: 14 October 2020; Accepted date: 13 November 2020.

Article type: Research article.

\section{Introduction}

Coatings play a vital role in the development of the civilizations based on the high technologies. Oxides like silica, zirconia, titania, and alumina have various electro, physical, optical, mechanical properties, which make them useful as a basis for the synthesis of many coating materials. Amongst these oxides, the zirconia-based coatings have a high potential owing to their outstanding properties such as the chemical inertness, optical transmission in the visible and IR region, high refractive index and bandgap, good adhesion to the substrates, high heat and corrosion resistance as well as high thermal stability. ${ }^{[1-3]}$ Zirconia based coatings are used for many purposes such as the optical filters, laser mirrors, thermal barrier coatings, and gate dielectric in microelectronic

\footnotetext{
${ }^{1}$ School of Physical Sciences, Solapur University, Solapur - Pune National Highway, Kegaon, Solapur - 413 255, Maharashtra, India

${ }^{2}$ Department of Physics, DKTE's Textile \& Engineering Institute, Ichalkaranji - 416115, Maharashtra, India

${ }^{3}$ State Key Laboratory of Catalysis, Dalian Institute of Chemical Physics, Chinese Academy of Sciences, Dalian - 116023, China

${ }^{4}$ Department of Materials Science and Engineering, Yonsei University, Seoul 120-749, Republic of Korea

*: E-mail: uzma.phys@gmail.com (U. Bangi)
}

devices. ${ }^{[4-6]}$ Different techniques have been employed for coating the zirconia viz. the sol-gel spin coating, atomic layer deposition (ALD), reactive sputtering and pulsed laser deposition etc.. ${ }^{[7-9]}$

The sol-gel spin coating is a simple and cost-effective technique, which produces large ceramics and glass bodies of high optical quality. ${ }^{[10]}$ But it has a major drawback of cracking the coatings, which is caused by the capillary forces. These forces are exerted by the surface tension of the solvent present in the pores during the drying stage. It has been studied that the effect of capillary forces can be reduced by using the drying controlled chemical additives (DCCAs) such as the oxalic acid (OA), glycerol (GLY), formamide (FA), dimethyl formaldehyde (DMF) etc. Therefore, to lower the cracking probability and to improve the optical transmission of the nanoporous materials such as aerogels and xerogels, various DCCAs have been used as reported elsewhere. ${ }^{[11,12]}$ Beside the nanoporous materials, many researchers have synthesized the optically transparent and crack-free zirconia coatings using various polymeric additives. For example, Qiu et al. have prepared zirconia membranes using polyvinyl alcohol (PVA), polyethylene glycol (PEG), polyacrylic acid (PAA) and methylcellulose $(\mathrm{MC}){ }^{[13]}$ Lee et al. further reported the sol- 
gel based zirconia biocoatings using PEG. ${ }^{[14]}$ However, to our knowledge there are rare reports on the preparation of the zirconia coatings employing DCCAs. As reported by Rao et al., amongst various DCCAs, GLY has been observed to improve the textural properties of the nanoporous materials because of its low vapor pressure. ${ }^{[12]}$

The GLY helps to reduce the refractive index of zirconia coatings and sustain their porous structure. This leads to improvements in the optical transmission and hydrophobicity of the zirconia coatings. These coatings can be applied as the active waveguide sensors and optical filters. Therefore, in the present work, attempts have been made to synthesize sol-gel based optically transparent and hydrophobic zirconia coatings using glycerol as DCCA. Further, the influences of different concentrations of the GLY on the chemical structure, hydrophobicity, morphology and optical properties of the zirconia coatings were studied by varying the molar ratio of GLY:Zr ${ }^{4+}$.

\section{Experimental section}

\subsection{Preparation of zirconia coatings}

For the synthesis of zirconia coatings, zirconium n-propoxide ( $\mathrm{ZrPrO}, \mathrm{Zr}\left(\mathrm{OC}_{3} \mathrm{H}_{7}\right)_{4}, 70 \%$ in n-PrOH, Sigma-Aldrich) was used as a precursor, n-propanol (n-PrOH, Duksan) as a solvent, acetylacetonate (Acac, $\mathrm{C}_{5} \mathrm{H}_{8} \mathrm{O}_{2}$, Sigma-Aldrich) as a chelating agent, glycerol (GLY, $\mathrm{C}_{3} \mathrm{H}_{8} \mathrm{O}_{3}$, SD Fine) as a drying control chemical additive (DCCA), aqueous hydrochloric acid (0.1 M) ( $\mathrm{HCl}$, SD Fine) as a catalyst. Further, $\mathrm{HCl}$ (conc.), ammonium hydroxide $\left(\mathrm{NH}_{4} \mathrm{OH}, \mathrm{SD}\right.$ Fine), ethanol (EtOH, SD Fine), acetone (SD Fine) and double-distilled water (D. I. $\mathrm{H}_{2} \mathrm{O}$ ) were used for cleaning the glass substrates. The glass substrates were cleaned following the procedures as explained. Initially, the substrates were cut into $2.5 \times 2.5 \mathrm{~cm}^{2}$ size and dipped in $\mathrm{HCl}$ (conc.) solution for one day. Afterwards, they were immersed in the $\mathrm{NH}_{4} \mathrm{OH}$ (conc.) for $60 \mathrm{~min}$. followed by the ultrasonic cleaning in D.I. $\mathrm{H}_{2} \mathrm{O}$ at $50^{\circ} \mathrm{C}$ for $30 \mathrm{~min}$. Finally, these substrates were rinsed in $\mathrm{EtOH}$ and acetone, and then dried in oven at $50^{\circ} \mathrm{C}$.

The preparation of zirconia alcosol was carried out using the sol-gel process. Initially, the $\mathrm{PrOH}$, Acac and $\mathrm{ZrPrO}$ were mixed together and the mixture was stirred for $10 \mathrm{~min}$. As seen in Reaction (1), a molecule was formed from the mixing of the $\mathrm{PrOH}$ and $\mathrm{ZrPrO}$, in which $\mathrm{PrOH}$ just co-ordinated to $\mathrm{ZrPrO}$. As given in Reaction (2), the Acac reacted with the $\mathrm{ZrPrO}$ to form the zirconium propoxide complex. ${ }^{[15]}$ Afterwards, GLY was added to this mixture (10 min. stirring) followed by the addition of $\mathrm{HCl}(0.1 \mathrm{M})$, which was again stirred for $60 \mathrm{~min}$. The addition of the GLY enhanced the pH (nearly 5) of the alcosol because of its weak acidic nature leading to the faster gelation. ${ }^{[12]}$ However, $\mathrm{HCl}$ caused the decrease in the $\mathrm{pH}$ (nearly 2-3) of the alcosol resulting in the slower gelation. The hydrolysis and condensation reactions of the precursor solution are given in the Reactions (3) to (5). The addition of a catalyst molecule to this complex formed a dimer of zirconium hydroxide complex (Reaction 3). Moreover, the reaction of four molecules of the catalyst also formed a dimer of the zirconium hydroxide (Reaction 4). The condensation of these dimers of zirconium hydroxide and complex formed a tetramer (Reaction 5), on which polycondensation resulted in the polymer of ziroconia. GLY remained in the pores of the 3D network of zirconia and helped to reduce the capillary pressure exerted by the pore fluid during the drying.

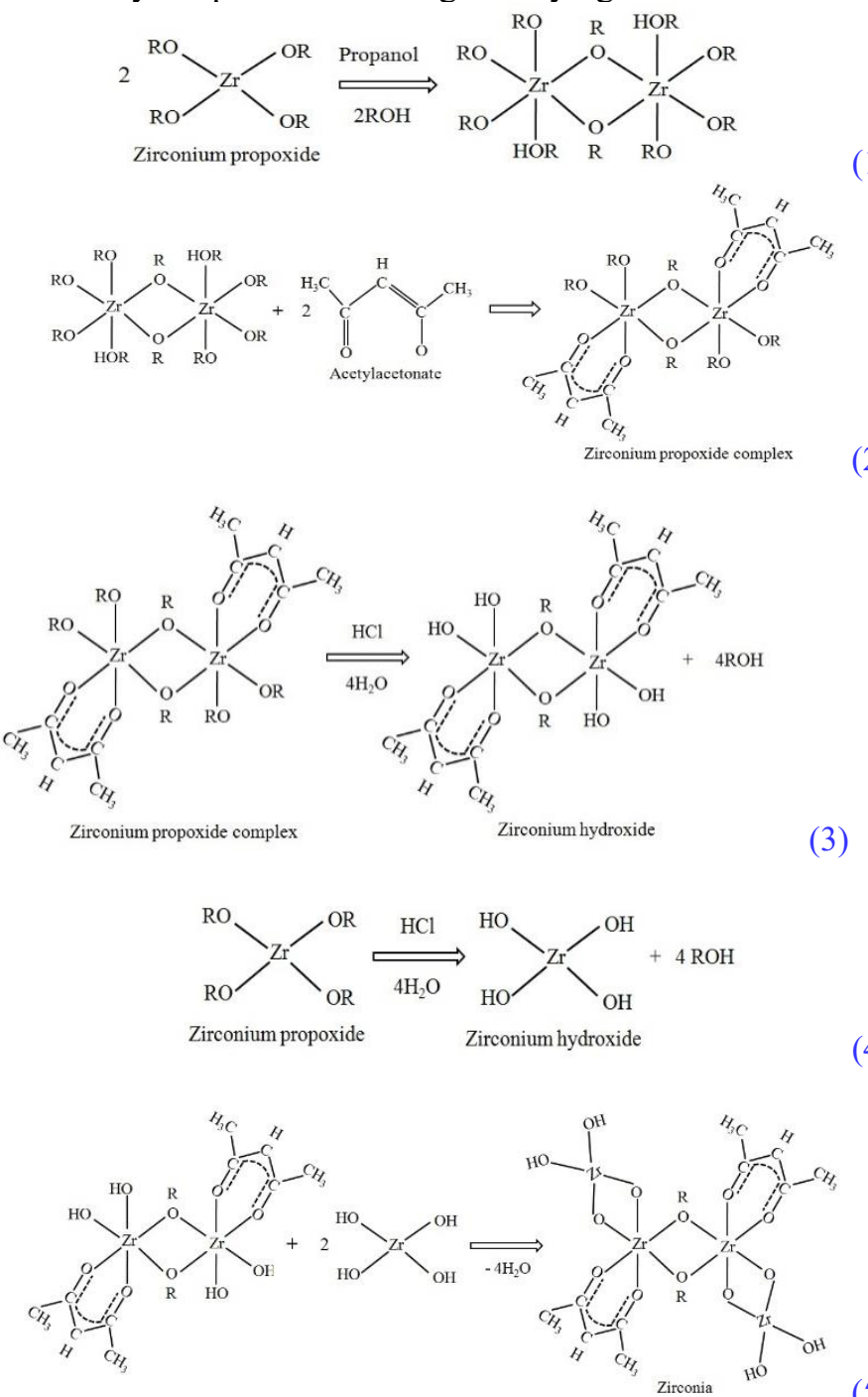

The zirconia alcosol was aged at room temperature for one day and used for the coating purpose. The deposition of zirconia was taken on the cleaned glass substrates using the spin coating technique. The zirconia alcosol was spin coated at 500, 1500, 1000 RPM for 10, 30 and 10 seconds respectively to form the coatings. Later, these coatings were dried at 50 and $150{ }^{\circ} \mathrm{C}$ in the proportional integral derivative (PID) controlled oven for the period of $60 \mathrm{~min}$. each. During the synthesis, the molar ratio of $\mathrm{ZrPrO}: \mathrm{PrOH}: \mathrm{Acac}: \mathrm{H}_{2} \mathrm{O}$ with $\mathrm{HCl}(0.1 \mathrm{M})$ was fixed for 1:79.8:0.62:35.08. Zirconia coatings were prepared by varying the molar ratio of $\mathrm{GLY}: \mathrm{Zr}^{4+}$ as 0 , $0.429,0.58,1.287,1.716$, and 2.145 and the corresponding samples were named as ZT1, ZT2, ZT3, ZT4, ZT5, and ZT6 respectively. The influence of the GLY: $\mathrm{Zr}^{4+}$ molar ratio on the chemical structure, hydrophobicity, morphology and optical properties of the zirconia coatings was studied.

\subsection{Characterizations of zirconia coatings}

The Fourier transform infrared spectroscopy (FT-IR, Thermo Scientific, USA) was employed for the identification of the chemical bonds present in the zirconia coatings.

Moreover, chemical bonding state of the coatings was 
analyzed by using the photoemission spectroscopy (PES) and near edge X-ray absorption fine structure (NEXAFS) at the 4D beamline of the Pohang Accelerator Laboratory (South Korea). The hydrophobic property of zirconia coatings was studied by measuring the contact angle using contact angle meter (RameHart instrument, USA). The morphological analysis of the zirconia coatings was carried out by utilizing the field emission scanning electron microscopy (Quanta 220F, FEI). The optical transmittance of the coatings was performed over 400-1000 $\mathrm{nm}$ wavelength range using the spectrophotometer (BIO-AGE UV-Vis $2800 \mathrm{PC}$ ). The porosity of the zirconia coatings was confirmed by calculating their refractive indices.

\section{Results and discussion}

GLY is a protic solvent having the lowest vapor pressure (2.13 x $10^{-6}$ bar at $20^{\circ} \mathrm{C}$ ) among other DCCAs. As shown in the chemical structure of GLY (Fig. 1), it consists of three hydroxyl groups, which are responsible for increasing the $\mathrm{pH}$ of the alcosol. The addition of GLY to the alcosol forms a protective shielding around the $\mathrm{Zr}$ preventing the faster gelation of zirconia. Moreover, the GLY facilitates the diffusion of water through pores and remains in the pores, causing the decrease in capillary pressure during the drying stage ${ }^{[11,12]}$ This may help to maintain the pores sizes in the zirconia coating. Therefore, the GLY is used as a DCCA for the preparation of the zirconia coatings. The effect of varying GLY concentration on various characteristics such as chemical structure, hydrophobicity, morphology as well as optical transmission of the zirconia coatings has been studied.<smiles>OCC(O)CO</smiles>

Fig. 1 Chemical structure of GLY.

\subsection{FTIR spectroscopy analysis}

Fig. 2 displays the FTIR spectra of the zirconia coating samples (ZT1-ZT6). As seen from Fig. 2, the peaks at around 506,627 and $754 \mathrm{~cm}^{-1}$ correspond to the $\mathrm{Zr}-\mathrm{O}$ vibrations of the zirconia, ${ }^{[16-18]}$ which evidence that the formed coating is zirconia. The presence of the absorption bands at around 1107 and $2992 \mathrm{~cm}^{-1}$ can be assigned to the C-C vibrations and asymmetric $\mathrm{C}-\mathrm{H}$ deformation of the $-\mathrm{CH}_{3}$ group of acetylacetonate attached to $\mathrm{Zr}$ cations and the $-\mathrm{CH}_{2}$ groups of GLY in zirconia samples. ${ }^{[19,20]}$ The peak intensity of the C-H band is higher in case of ZT2 sample compared to other zirconia samples. This manifests the presence of many molecules of the Acac attached to the $\mathrm{Zr}$ as well as the GLY in the pores of zirconia. The presence of the $\mathrm{C}-\mathrm{C}$ and $\mathrm{C}-\mathrm{H}$ bonds can be confirmed from the Reaction (5). Further, the peaks at around $906 \mathrm{~cm}^{-1}$ corresponds to the $\mathrm{Zr}-\mathrm{O}-\mathrm{Si}$ bond, which may be due to the scratching of the zirconia coatings from the silica substrate.

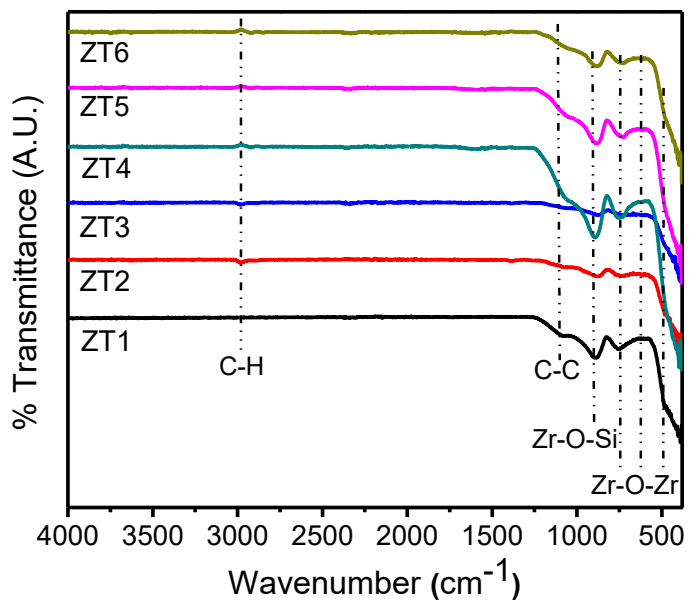

Fig. 2 FTIR spectra of zirconia samples with varying molar ratio of GLY: $\mathrm{Zr}^{4+}$.

\subsection{XPS analysis}

Moreover, the chemical bonding states of the zirconia coating samples were analyzed from XPS spectra as presented in Fig. 3. The peaks at the binding energies (B.E.) of around 99.15, 182.5, 285 and 530-532 eV are assigned to the $\mathrm{Si} 2 \mathrm{p}, \mathrm{Zr} 3 \mathrm{~d} 5 / 2$, $\mathrm{C} 1 \mathrm{~s}$, and $\mathrm{O} 1 \mathrm{~s}$ states of the zirconia respectively. ${ }^{[14]}$ These peaks correspond to the $\mathrm{Zr}-\mathrm{O}(530.0 \mathrm{eV}), \mathrm{C}=\mathrm{O}$ and $\mathrm{Zr}-\mathrm{OH}(531.6$ $\mathrm{eV}$ ), respectively. The $\mathrm{C} 1$ s peaks correspond to the $\mathrm{C}=\mathrm{O}, \mathrm{C}-\mathrm{C}$ and $\mathrm{C}-\mathrm{H}$ bonds remained in the zirconia samples due to the Acac and GLY. All these bonding states match well with the results of FTIR (Fig. 2) and can also be confirmed from Reaction (5).

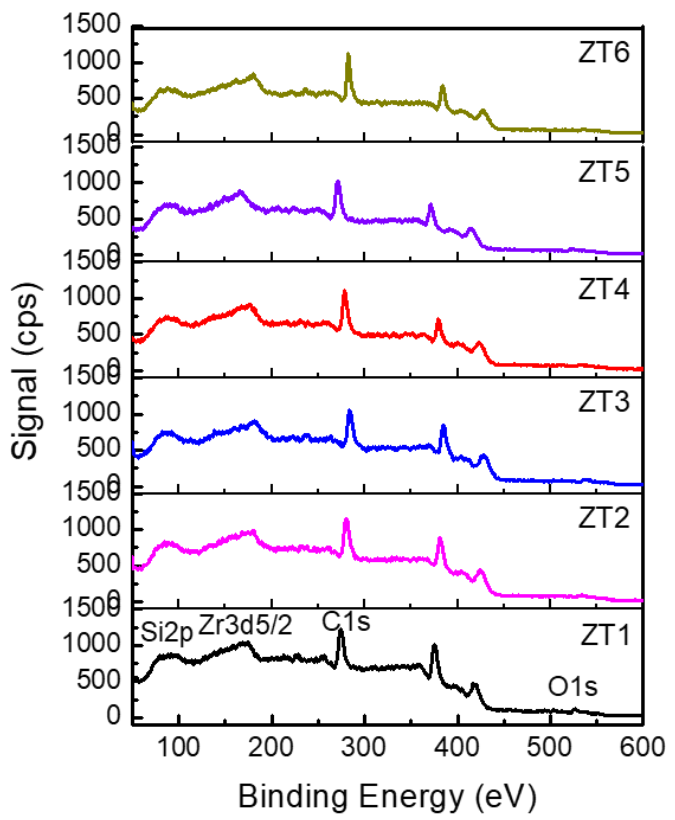

Fig. 3 XPS spectra of zirconia samples with varying molar ratio of GLY:Zri ${ }^{4+}$.

\subsection{Contact angle measurement}

The hydrophobic characteristic of zirconia samples was studied by measuring their contact angles as shown in Fig. 4. From Fig. 4, it is obvious that with the addition of GLY to the zirconia alcosol, the contact angle of the zirconia coating is 
increased. The unmodified zirconia sample ZT1 has a low contact angle of $98^{\circ}$, while the GLY modified zirconia sample ZT2 exhibits a contact angle of $108^{\circ}$. The contact angle is decreased with further increase in the GLY: $\mathrm{Zr}^{4+}$ molar ratio (from samples ZT2 to ZT6). The reason behind this may be ascribed to the fact that with the increase in the GLY: $Z^{4+}$ molar ratio, the number of hydroxyl groups (of GLY as seen from Fig. 1) in the zirconia is increased. These hydroxyl groups are responsible for reducing the hydrophobicity of zirconia samples causing the decrease in their contact angle. It indicates that a small amount of the GLY is sufficient for maintaining the pore structure in the zirconia sample during the drying stage. These results are in good agreement with the high C-H bond peak intensity for the ZT2 sample in the FTIR spectra (Fig. 2).

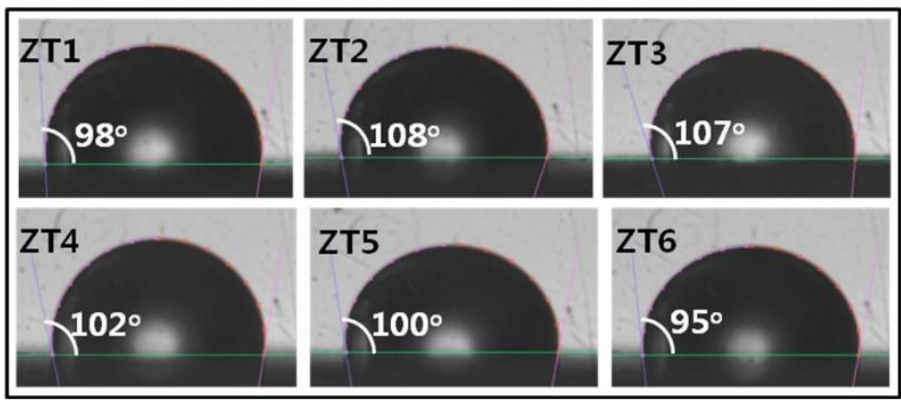

Fig. 4 Water droplets on the surface of zirconia samples and their measured contact angles.

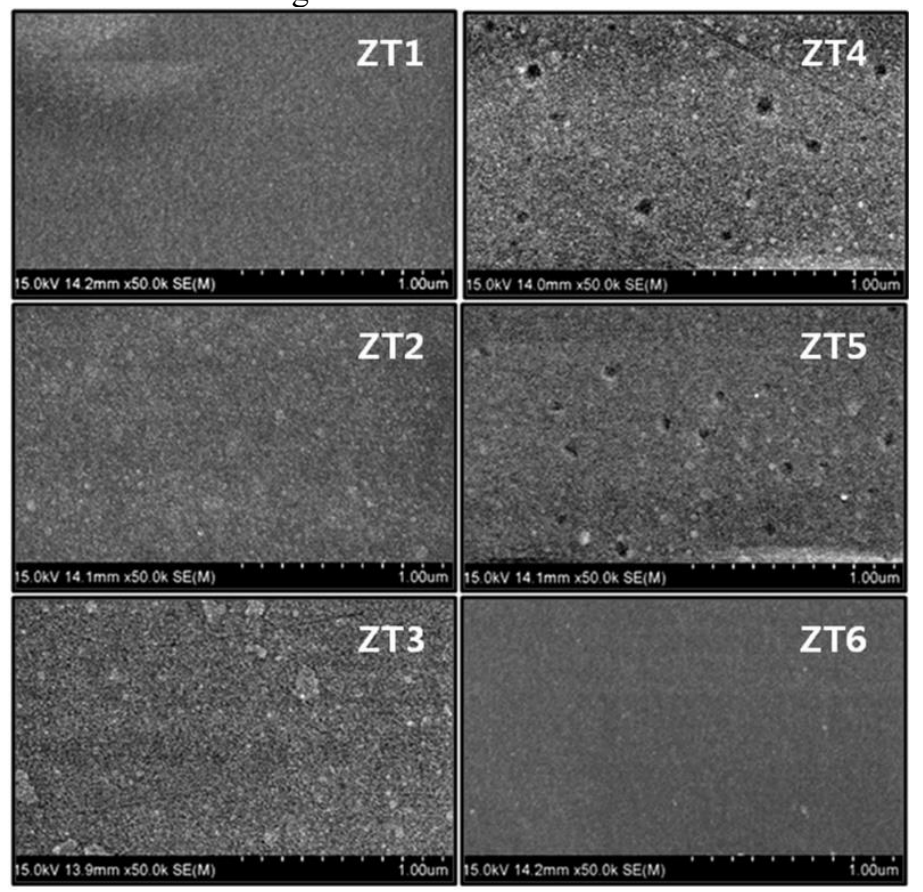

Fig. 5 SEM micrographs of zirconia samples with varying molar ratio of GLY:Zr ${ }^{4+}$.

\subsection{SEM observation}

The SEM micrographs of the pristine and the GLY modified zirconia coating samples are shown in Fig. 5. From Fig. 5, it is obvious that the microstructure consisted of the spherical particles with a good connectivity between them. The surface of zirconia samples is observed to be well developed and crack free. This may be owing to the presence of GLY, which helps to reduce the stress on the pores and to maintain the porous structure during drying. ${ }^{[2]}$ The particles and pore sizes are observed to be very small in case of the ZT1 and ZT6 samples compared to other zirconia samples. While the ZT2-ZT5 samples exhibited the porous morphologies with larger particles sizes. Amongst ZT2-ZT5 samples, ZT2 and ZT3 showed the uniform surface, whereas ZT4 and ZT5 exhibited the micro-holes on their surface. The micro-holes on the surface of ZT4 and ZT5 samples are due to the fast evaporation of the solvent. The porous morphologies of ZT2 and ZT3 evidenced the high contact angles of these samples as confirmed from the contact angle measurements (Fig. 4). The high contact angles are due to the nanoporous characteristics of the surfaces, on which the water remained as a droplet instead of spreading on the surface.

\subsection{Optical transmission and dielectric constant measurement}

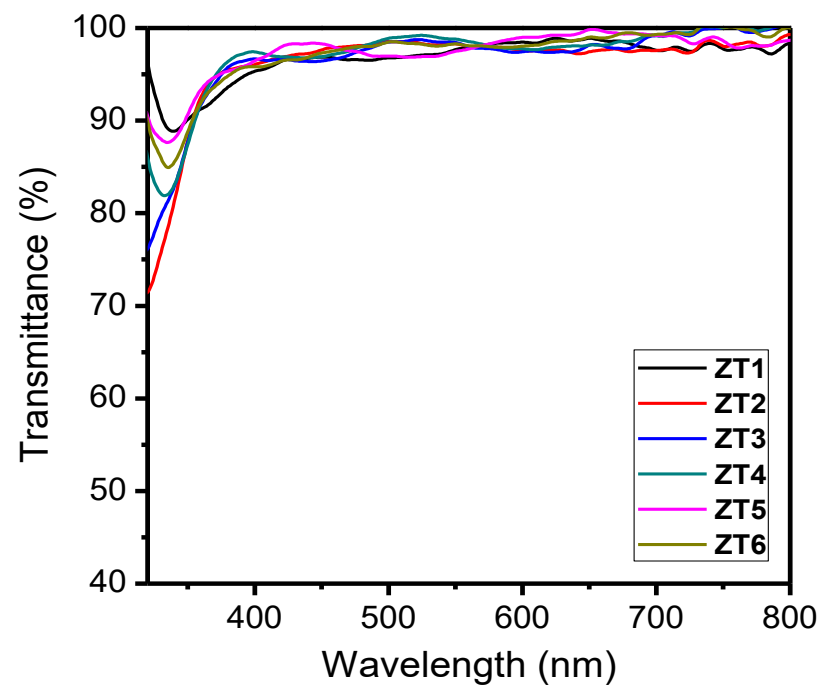

Fig. 6 Transmission spectra of zirconia samples with varying molar ratio of GLY: $\mathrm{Zr}^{4+}$.

The transmission spectra of the zirconia coating samples are plotted as shown in Fig. 6. From Fig. 6, it is seen that all the zirconia samples exhibit the high optical transmission greater than $90 \%$. The high optical transmission is attributed to the improvement in the structural and surface homogeneity as well as a decrease in the refractive index of the zirconia samples. The refractive indices $\left(\mathrm{n}_{\mathrm{c}}\right)$ of the zirconia samples were calculated using Equation (1): ${ }^{[22]}$

$$
R_{c}=\frac{\left(\mathrm{n}_{\mathrm{c}}^{2}-\mathrm{n}_{\mathrm{sub}}\right)^{2}}{\left(\mathrm{n}_{\mathrm{c}}^{2}+\mathrm{n}_{\mathrm{sub}}\right)^{2}}
$$

where $R_{c}$ is the reflection coefficient of the zirconia coating and $\mathrm{n}_{\text {sub }}$ is the refractive index of the substrate which is taken to be 1.513. The $R_{c}$ is found out using Equation (2).

$$
R_{c}=1+\frac{T}{\mathrm{R}_{\text {sub }}-1}
$$

where $T$ is the transmission coefficient and $\mathrm{R}_{\text {sub }}$ is the reflection coefficient of the substrate. $T=0.958$ is used for the 
calculation of $R_{c}$ (Fig. 6). Further, $\mathrm{R}_{\text {sub }}$ is calculated using Equation 3.

$$
\mathrm{R}_{\text {sub }}=\frac{\left(\mathrm{n}_{\mathrm{a}}-\mathrm{n}_{\text {sub }}\right)^{2}}{\left(\mathrm{n}_{\mathrm{a}}+\mathrm{n}_{\text {sub }}\right)^{2}}
$$

where $n_{a}(=1)$ and $n_{\text {sub }}(=1.513)$ are the refractive indices of the air and glass substrate. Thus, the refractive indices $\left(n_{c}\right)$ of different zirconia coating samples were determined using the Formulae (1) - (3) and the obtained $n_{c}$ were in the range from 1.66 to 1.9 .

The graph of the calculated $n_{c}$ and the measured contact angles of the zirconia coating samples is plotted as shown in Fig. 7. From Fig. 7, it is observed that with the increase in GLY: $\mathrm{Zr}^{4+}$ molar ratio from ZT1 to ZT2, the $n_{c}$ decreased while the contact angle increased, exhibiting the enhancement in porosity of the ZT2 sample. ${ }^{[21]}$ Further increase in the GLY:Zr ${ }^{4+}$ molar ratio from ZT2 to ZT6 led to an increase in their $n_{c}$ and decrease in their contact angles. The high optical transmission and porosity of of the ZT2 sample (GLY:Zr4+ molar ratio of 0.429 ) is evidenced from its low refractive index $(\sim 1.66) .{ }^{[22]}$ Thus, all of the above results showed that a small amount of GLY is sufficient to improve the optical transmission, porosity as well as hydrophobicity of the zirconia coatings.

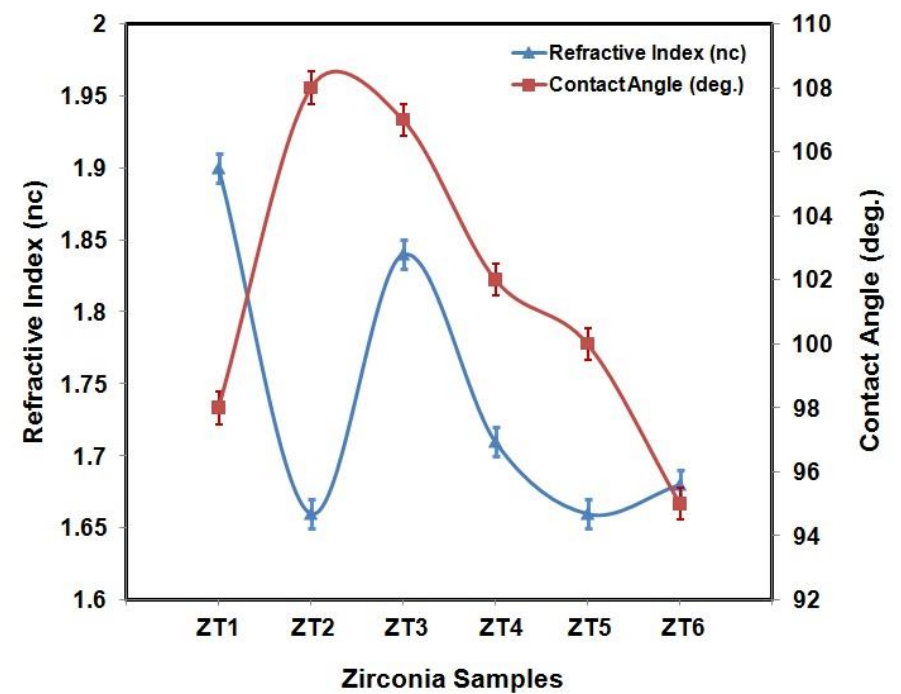

Fig. 7 Influence of varying molar ratio of GLY: $\mathrm{Zr}^{4+}$ on the refractive indices and contact angles of zirconia samples

\section{Conclusions}

Optically transparent, hydrophobic and porous zirconia coatings have been successfully prepared using GLY as DCCA. The hydrophobicity of the zirconia coatings was enhanced with the addition of GLY as confirmed from the FTIR spectra and contact angle measurements. SEM micrographs clearly exhibited the formation of crack free and homogeneous zirconia coatings. Moreover, the addition of GLY helped to reduce the refractive index of the zirconia coatings, leading to the improvement in their optical transmission and porous characteristics. Thus, the optically transparent (>90\%), hydrophobic $\left(\theta \sim 108^{\circ}\right)$ and porous zirconia coatings with a low refractive index $(\sim 1.66)$ were obtained using the molar ratio of GLY: $\mathrm{Zr}^{4+}$ equal to 0.429 . These zirconia coatings can be used as the optical filters in the UV and VIS region of spectrum.

\section{Acknowledgement}

This study was financially supported by the Department of Science and Technology- Science \& Engineering Research Board (DST-SERB), New Delhi, India, through a major research project on 'aerogels' (no. SB/FTP/PS-030/2014).

\section{Conflict of Interest}

There is no conflict of interest

\section{Supporting Information}

Not applicable

\section{References}

[1] H. Bensouyad, H. Sedrati, H. Dehdouh, M. Brahimi, F. Abbas, H. Akkari, R. Bensaha, Thin Solid Film., 2010, 519, 96-100, doi: 10.1016/j.tsf.2010.07.062.

[2] J. Mosa, O. Fontaine, P. Ferreira, R. Borges, V. Vivier, D. Grosso, C. Loberty-Robert, C. Sanchez, Electro. Act., 2011, 56, 7155-7162, doi: 10.1016/j.electacta.2011.05.074.

[3] M. T. Soo, N. Prastomo, A. Matsuda, G. Kawamura, H. Muto, A. Noor, Z. Lockman, K. Cheong, App. Surf. Sci., 2012, 258, 5250-5258, doi: 10.1016/j.apsusc.2012.02.008

[4] E. Otal, P. Angelome, S. Bilmes, G. Soler-Illia, Adv. Mater., 2006, 18, 934-938, doi. 10.1002/adma.200502215.

[5] A. Gambardella, M. Berni, A. Russo, M .Bianchi, Surf. \& Coat. Techno., 2018, 337, 306-312, doi: 10.1016/j.surfcoat.2018.01.026.

[6] K. Joy, S. S. Lakshmy, P. B. Nair, G. P. Daniel, J. Allo. Comp., 2012, 512, 149-155, doi: 10.1016/j.jallcom.2011.09.051.

[7] E. Krumov, J. Dikova, K. Starbova, D. Popov, V. Blaskov, K. Kolev and L.D. Laude, J. Mater. Sci., 2003, 14, 759760, doi: 10.1023/A:1026176431171.

[8] A. Anders, Surf. Coat. Tech., 2005, 200, 1893-1906, doi: 10.1016/j.surfcoat.2005.08.018.

[9] P. Martin, Handbook of deposition technologies for films and coatings, third edition, 2010, pp. 277-278, Elsevier, United State.

[10] E.J.A. Pope and J.D. Mackenzie, in Better Ceramics through Chemistry II, edited by C.J. Brinker, D.E. Clark, and D.R. Ulrich, Pittsburg, PA, 1986, pp. 809.

[11] D. Harnath, A. V. Rao and P. B. Wagh, J. Por. Mater., 1999, 6, 55-62, doi: 10.1023/A:1009649403740.

[12] A. P. Rao, A. V. Rao, J. Mater. Syn. Proc., 2002, 10, 7-16, doi: 10.1023/A:1021040727829.

[13] M. Qui, Y. Fan, N. Xu, J. Memb. Sci., 2010, 348, 252-259, doi: 10.1016/j.memsci.2009.11.009.

[14] H. Lee, J. Liao, P. Shao, C. Yao, Y. Lin, Y. Juang, J. Sol-Gel Sci. \& Techno., 2016, 77, 574-584, doi: 10.1007/s10971015-3885-z.

[15] G. I. Spijksma, H. J. M. Bouwmeester, D. H. A. Blank and V. G. Kessler, Chem. Commun., 2004, 16, 1874 -1875, doi: 10.1039/b406012a.

[16] M. R. Elvira, M. A. Mazo, A. Tamayo, F. Rubio, J. Rubio, J. L. Oteo, J. Chem. Chem. Eng., 2013, 7, 120-131, Corpus ID: 
91390007.

[17] C. J. Fu, Z. W. Zhan, M. Yu, S. M. Lei, J. H. Liu, L. Dong, Int. J. Electrochem. Sci., 2014, 9, 2603-2619, ISSN 14523981.

[18] U. Bangi, B. Patil, R. Pawar, H. Park, Macromol. Symp., 2019, 393(1), $2000036 \quad$ (6 pgs), doi: 10.1002/masy.202000025.

[19] U. K. H. Bangi, C. S. Park, S. Baek, H. H. Park, Powder Techno., 2013, 239, 314-318, doi: 10.1016/j.powtec.2013.02.014.

[20] S. S. Latthe, R. S. Sutar, T. B. Shinde, S. B. Pawar, T. M. Khot, A. K. Bhosale, K. K. Sadasivuni, R. Xing, L. Mao, S. Liu, ACS Appl. Nano Mater., 2019, 2(2), 799-805, doi: 10.1021/acsanm.8b02021.

[21] W.H. Lan, P. Xiao, J. Am. Ceram. Soc., 2007, 90, 27712778, doi: 10.1111/j.1551-2916.2007.01839.x.

[22] K. Joy, I.J. Berlin, P.B. Nair, J.S. Lakshmi, G.P. Daniel, P.V. Thomas, J. Phys. Chem. Sol., 2011, 72, 673-677, doi: 10.1016/j.jpcs.2011.02.012.

\section{Author information}

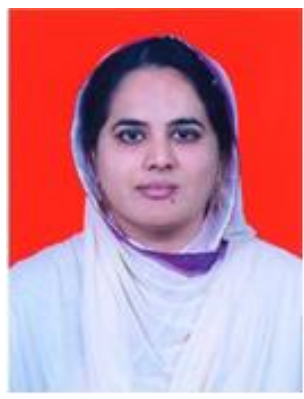

Miss Uzma Bangi is a DST Women Scientist in School of Physical Sciences, PAH Solapur University. She received her doctorate from Shivaji University, under the guidance of Prof. A. V. Rao in 2011. She worked as the Brain Korean -21 Fellow in Yonsei University and is the recipient of Young Scientist Fellowship honored by Science and Engineering Research Board (SERB), Gov. of India. Her research interests are low-cost Aerogels and Coatings.

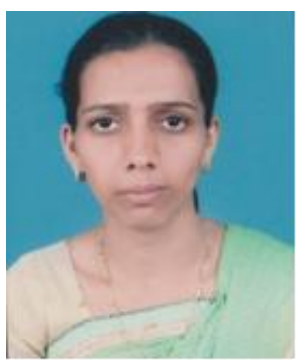

Mrs. Rabiya Gafari is an Assistant Professor in Department of Physics, DKTE's Textile \& Engineering Institute, Ichalkaranji $(M H)$, India. She completed her M. Sc. and B. Ed. from Shivaji University in 2007-08. She has eleven years of the teaching experience in engineering college. Her research interests are thin films and their applications.

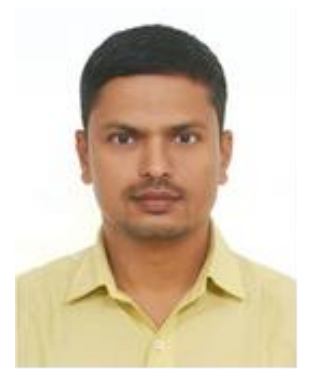

Mr. Rajendra Pawar is a President's International Postdoctoral Fellow in Dalian Institute of Chemical Physics (DICP), China. He received his doctorate from Shivaji University in 2011. He worked as the Research Professor in Hanyang University, Republic of Korea from 2011 to 2017. His research interests are Photo-thermocatalytic dry reforming reaction ( $\mathrm{CO}_{2}$ and $\mathrm{CH}_{4}$ conversion), Photocatalytic water splitting and detoxification, and synthesis of energy nanomaterials.

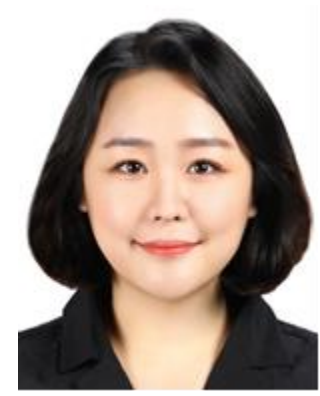

Hae-Noo-Ree Jung is pursuing her PhD degree in the Department of $\mathrm{Ma}$ terials Science and Engineering at Yonsei University. She received her $B S$ degree from Hongik University in 2011. The main topic of her study is metal oxide aerogels and nanowire incorporated nano composite by using sol-gel process. Her research interests include sol-gel parameter control for porosity and thermal conductivity of nanaoporous metal oxides aerogel powder for applying to thermal insulator.

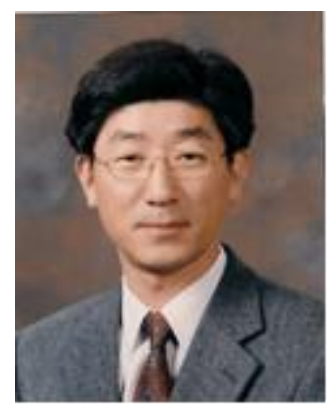

Hyung-Ho Park is a professor of Material Science and Engineering at Yonsei University. His research interest is characterization of a various type of materials and designing microstructure. Recently, he mainly focuses on various oxide nano-porous structures based on solution processes, microstructure fabrication, surface treatment, heat-resistant mesoporous materials and electronic devices.

Publisher's Note Engineered Science Publisher remains neutral with regard to jurisdictional claims in published maps and institutional affiliations. 